\title{
Comparison of histamine and methacholine for use in bronchial challenge tests in community studies
}

\author{
B G HIGGINS, J R BRITTON, S CHINN, T D JONES, A S VATHENEN, \\ P G J BURNEY, A E TATTERSFIELD
}

From the Department of Respiratory Medicine, City Hospital, Nottingham, and the Department of Community Medicine, St Thomas's Hospital, London

\begin{abstract}
Measurement of bronchial reactivity is widely used in epidemiological surveys. Histamine has been compared with methacholine inhalation challenge in two samples of adults from a small town to determine which is the better agent for use in community studies. Increasing doses of histamine and methacholine were given, up to a maximum of 4 and $12 \mu \mathrm{mol}$ respectively, according to the method of Yan et al, the provocative dose of agonist causing a $20 \%$ fall in $\mathrm{FEV}_{1}\left(\mathrm{PD}_{20}\right)$ being measured. More subjects had a measurable $\mathrm{PD}_{20}$ with methacholine than with histamine, both in a random sample of 108 subjects $(25 v 11$ subjects, $\mathrm{p}<0.01)$ and in an additional 95 subjects selected because of wheeze in the last 12 months $(67 v 48$ subjects, $\mathrm{p}<0.01)$. Side effects were mild with both agents but histamine caused voice change in more subjects $(21 \% v 11 \%)$. Repeatability was assessed in a further group of subjects with wheeze in the last year. The $95 \%$ range for a single estimation of $\mathrm{PD}_{20}$ in subjects with a measured $\mathrm{PD}_{20}$ on at least one occasion was \pm 2.5 doubling doses for histamine $(\mathrm{n}=25)$ and $\pm 2 \cdot 1$ doubling doses for methacholine $(\mathrm{n}=33)$. Thus methacholine has advantages over histamine for community studies of bronchial reactivity as it is possible to use doses that produce more $\mathrm{PD}_{20}$ measurements with fewer side effects.
\end{abstract}

\section{Introduction}

Bronchial reactivity has been used as an objective marker of asthma in epidemiological surveys, and there is growing interest in the distribution of this measurement in the population. ${ }^{1-8}$ The importance of using a standardised bronchial challenge test is well recognised, but which of the available tests is best suited to epidemiological work has not been determined. For community studies a test must be quick, repeatable, and readily acceptable. It should also provide a measure of reactivity in as large a proportion of the general population as possible. With tests such as exercise or cold air hyperventilation the maximum stimulus that can be achieved is inadequate to produce bronchoconstriction in most non-asthmatic individuals. With pharmacological agents such as histamine and methacholine the dose that can be given is limited by side effects.

Histamine and methacholine are the two agonists

Address for reprint requests: Dr B G Higgins, Department of Respiratory Medicine, City Hospital, Nottingham NG5 1 PB.

Accepted 9 May 1988 used most widely for inhalation challenge. In laboratory comparisons in patients with asthma there is close agreement between the provocative doses causing a $20 \%$ fall in $\mathrm{FEV}_{1}\left(\mathrm{PD}_{20}\right)$ for the two agents and repeatability has usually been similar, although there has been a suggestion that methacholine may produce fewer side effects for a given degree of bronchoconstriction. ${ }^{9}$ If this is true in a community setting methacholine would have an important advantage over histamine for epidemiological surveys. We have therefore compared histamine and methacholine inhalation challenge in a community study.

The study also evaluated serial peak flow measurements as an alternative to bronchial challenge tests. This is mentioned in the "Methods" section because it was incorporated into the study design, but the results will be described separately. This report is confined to the comparison of histamine and methacholine challenge tests.

\section{Methods}

SUBJECTS

The study was conducted in a small town of some 6500 adults, situated about $10 \mathrm{~km}$ from Nottingham. The 
only general practice in the town has 7800 patients aged 18-75 years on its list, and this includes nearly all the town's residents. Six copies of a simple questionnaire on respiratory symptoms were delivered to each household in the town with a request that every adult should complete and return one copy.

Two groups of subjects were recruited. Group A consisted of 199 subjects aged 18-75 years, drawn from the general practice age-sex register as a systematic random sample. The subjects were sent a letter countersigned by their own general practitioner explaining the purpose and nature of the study, asking them to take part, and enclosing an appointment time and a stamped, addressed envelope for reply. It was made clear that one of the practitioners was available to answer questions about the project. Subjects who did not respond were sent a second invitation. If this produced no reply an attempt was made to contact the subject by telephone or with a visit to his or her home. Subjects who were found to have left the town were replaced by new ones chosen at random from the agesex register.

Group B consisted of the first 400 people replying to the questionnaire who admitted to wheeze or whistling in the chest within the last year or to having a diagnosis of asthma. Appointments were made in the same way as for group A, but a second approach was not made to non-responders. Informed consent was obtained from all subjects. The study was approved by the Nottingham City Hospital ethics committee.

\section{STUDY DESIGN}

Group A subjects were randomly allocated either to undergo a bronchial challenge test or to record peak flow readings for a week. Subjects allocated to bronchial challenge were further randomised to undergo either a histamine or a methacholine test. On completion of the first challenge test the subjects were asked to return at the same time on another day to perform a second test with the alternative agonist; after this was completed they were asked to record peak flow readings for a week. Subjects who were initially allocated to the group making peak flow recordings were asked on completing these to undergo a bronchial challenge test, and subsequently a repeat test with the alternative agonist.

The procedure for group B was the same except that after the first bronchial challenge test the subjects were again randomised and half received the same agonist, so that repeatability could be assessed.

\section{BRONCHIAL CHALLENGE TESTS}

The invitation to take part in the study included a request to abstain from cigarettes for six hours, bronchodilator inhalers for six hours, and antihistamines for 24 hours before attending the test centre.
On arrival subjects rested for 5-10 minutes while the $\overrightarrow{\vec{F}}$ test procedure was explained, and a questionnaire on $\stackrel{5}{\rightarrow}$ respiratory symptoms and recent illness was completed.

Baseline $\mathrm{FEV}_{1}$ and forced vital capacity (FVC) were $\frac{\overline{\bar{D}}}{\bar{\phi}}$ measured with a dry bellows spirometer $\stackrel{0}{\circ}$ (Vitalograph), the higher of two successive readings $\%$ within $5 \%$ of each other being used. Challenge testing $\overrightarrow{0}$ was not performed in subjects whose baseline $\mathrm{FEV}_{1}$ was less than $60 \%$ predicted, in subjects who were $\vec{\sigma}^{\circ}$ pregnant, or in those who had had a recent serious illness.

The bronchial challenge test was based on that $\vec{\omega}$ described by Yan et $a l^{10}$ and used De Vilbiss No $40 \%$ nebulisers that had been shown by prior testing to have $\stackrel{\circ}{\circ}$ an output in the range $0.0025-0.0035 \mathrm{ml}$ per activation. After baseline spirometric measurements subjects inhaled normal saline followed by increasing $\vec{D}$ doses of histamine or methacholine. FEV $_{1}$ was measured one minute after each inhalation, the higher $\frac{c}{\rho}$ of two successive readings within $5 \%$ of each other $\stackrel{+}{-}$ being taken, and this was followed immediately by $œ$ administration of the next dose. In subjects with asthma or recent wheeze the test started with 0.03 O $\mu \mathrm{mol}$ histamine or $0.048 \mu \mathrm{mol}$ methacholine, followed by doubling dosage increments. All other subjects started with $0.06 \mu \mathrm{mol}$ histamine or $0.096 \mu \mathrm{mol} \approx$ methacholine and continued with quadrupling $\mathscr{\perp}$ increments, changing to doubling increments if the $\vec{\overrightarrow{ }}$ FEV fell by $10-19 \%$. The test was stopped if the FEV $\frac{3}{3}$ fell by $20 \%$ or more, or when the subject had received a maximum cumulative dose of $4 \mu \mathrm{mol}$ histamine or 12 ? $\mu \mathrm{mol}$ methacholine (doses rounded to the nearest integer). These doses were chosen because they응 produced approximately equal side effects in a small $\underset{\times}{\times}$ pilot study. At the end of the test any side effects experienced by the subjects were elicited by means of a standard questionnaire.

\section{SKIN TESTS}

Skin prick tests for Dermatophagoides pteronyssinus, $\frac{7}{O}$ grass pollen, and cat dander, with histamine and saline controls, were performed on the ventral aspect of the $N$ forearm at the time of the first challenge test. Weal size $N$ was measured as described previously.' Subjects were N regarded as atopic if the mean weal diameter was $2 \mathrm{~mm}$ or more with any allergen and $1 \mathrm{~mm}$ or less with saline.

\section{ANALYSIS OF RESULTS}

The provocative dose of histamine $\left(\mathrm{PD}_{20} \mathrm{H}\right)$ or methacholine $\left(\mathrm{PD}_{20} \mathrm{M}\right)$ producing a $20 \%$ fall in $\mathrm{FEV}_{1}$ from the post-saline value was determined by a curve fitting method, " with extrapolation to one doubling dose $\frac{\rho}{\mathbb{P}}$ above the maximum dose administered. $\mathrm{PD}_{20}$ values above this dose are described as "censored," and assigned a value at the upper limit of the estimated 
rarige ( $8 \mu \mathrm{mol}$ histamine or $24 \mu \mathrm{mol}$ methacholine). Base 10 logarithmic transformations of $\mathrm{PD}_{20}$ were used in all analyses.

Among subjects who completed both challenge tests the number of measurable $\mathrm{PD}_{20} \mathrm{H}$ and $\mathrm{PD}_{20} \mathrm{M}$ values were compared by McNemar's test. To allow the two agents to be compared over an approximately equipotent dose range a second $\mathrm{PD}_{20} \mathrm{M}$ was derived from data up to the $6 \mu \mathrm{mol}$ dose only, with extrapolation to $12 \mu \mathrm{mol}$ (these figures for relative potency are based on a previous laboratory study ${ }^{9}$ suggesting that $4 \mu \mathrm{mol}$ histamine is similar in its bronchoconstrictor activity to $6 \mu \mathrm{mol}$ methacholine).

Side effects from the two agents among subjects completing both challenge tests were compared by $\chi^{2}$ analysis. Side effects were also analysed from the first test on each subject, to avoid potential bias from subsequent non-attenders.

Repeatability was expressed in terms of the $95 \%$ range for a single measurement. The standard deviations of the differences between repeat results with histamine and with methacholine were used to calculate the expected standard deviation of the within person difference between between $P_{20} \mathrm{H}$ and $\mathrm{PD}_{20} \mathrm{M}$ results, and this was compared with the observed difference.

\section{Results}

\section{PARTICIPATION RATES}

The numbers of subjects participating in the two groups are shown in figure 1 .

The total response rate in group A was $73 \%$ (145 subjects), with 15 subjects only recording peak flow rates. Of the 130 subjects who attended for at least one challenge test, 108 completed both tests and 22 had only one because spirometric readings were too low or because of subsequent non-attendance. In group B, the group with wheeze in the last year, 257 subjects $(64 \%)$ kept at least one appointment and 234 attended for at least one challenge test. Ninety five completed challenge tests with histamine and methacholine, 50 completed repeat challenge tests with histamine and 46 repeat methacholine tests. One repeat histamine study was not included in the analysis because the subject's spirometry technique was unsatisfactory. There were 39 atopic subjects and 26 current smokers in group A ( $36 \%$ and $24 \%$ of the total); the corresponding figures in group B were 109 and 41 (57\% and 22\%).

\section{ESTIMATES OF PD $_{20}$}

The numbers of subjects from groups $A$ and $B$ with a measurable $\mathrm{PD}_{20}$ are shown in the table. Of the 108 subjects in group A who completed both tests, 11 $(10 \%)$ had a $\mathrm{PD}_{20} \mathrm{H}$ below $8 \mu \mathrm{mol}$ compared with 25 $(23 \%)$ with a PD $_{20} \mathrm{M}$ below $24 \mu \mathrm{mol}(\mathrm{p}<0.01)$ and 16 with a $\mathrm{PD}_{20} \mathrm{M}$ below $12 \mu \mathrm{mol}(\mathrm{p}>0 \cdot 1)$. Of the 95 subjects in group $B$ who carried out both tests, 48 had a $\mathrm{PD}_{20} \mathrm{H}$ below $8 \mu \mathrm{mol}$ and 67 a $\mathrm{PD}_{20} \mathrm{M}$ below $24 \mu \mathrm{mol}$ $(50 \% \vee 70 \%, \mathrm{p}<0.01)$.

\section{RELATION BETWEEN PD $_{20} \mathrm{H}$ AND PD $_{20} \mathrm{M}$}

The relation between $P_{20} \mathrm{H}$ and $\mathrm{PD}_{20} \mathrm{M}$ values for the 78 subjects from group A and group $B$ who had a measurable $\mathrm{PD}_{20}$ on at least one occasion is shown in figure 2. The regression coefficient (SE) of $\log _{10}\left(P D_{20} M\right)$ on $\log _{10}\left(P_{20} H\right)$ was $0.72(0 \cdot 10)$ and the intercept was $0 \cdot 15$. This was not altered significantly when smokers or atopic subjects were considered separately (regression coefficients $(\mathrm{SE})=0.72(0 \cdot 16)$

\section{Group A}

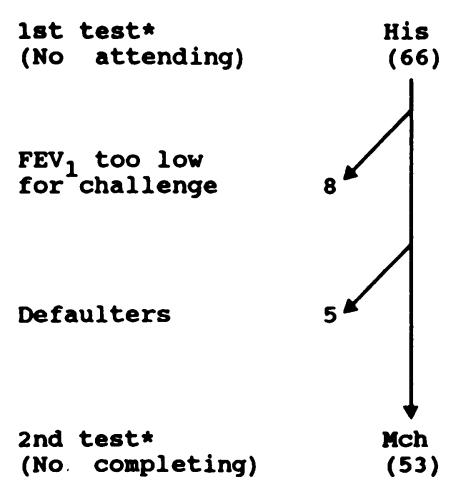

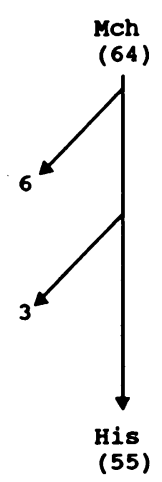

Group B
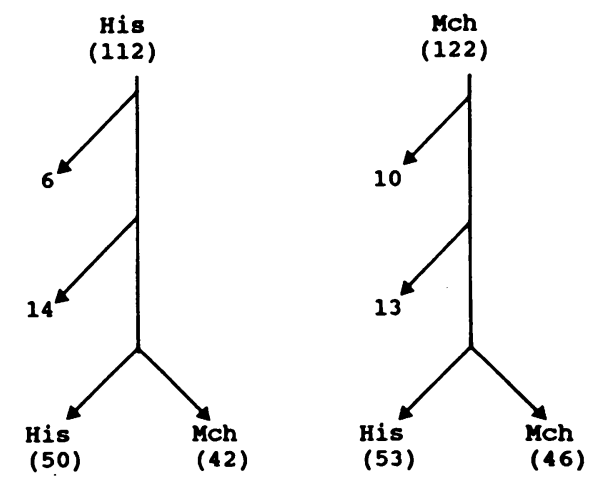

Fig 1 Number of subjects attending and completing bronchial challenge tests.

*His-histamine challenge test; Mch-methacholine challenge test. 


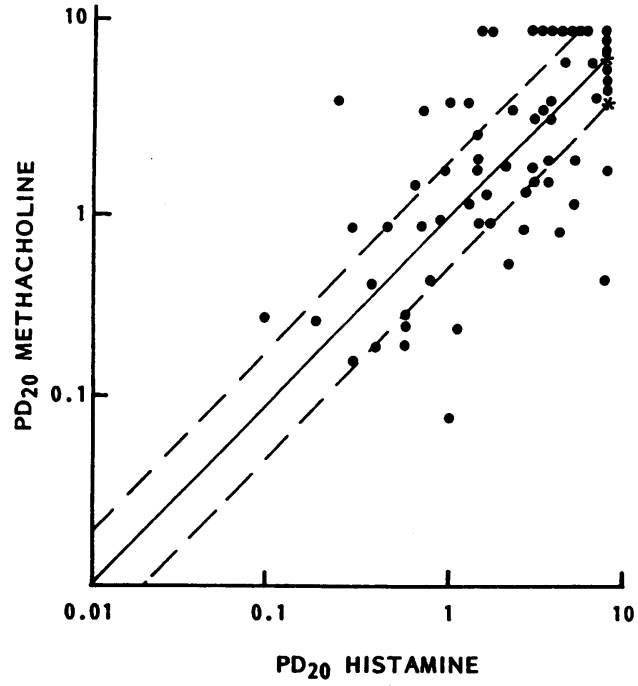

Fig 2 Relation between $P D_{20} H$ and $P D_{20} M$ (provocative dose of histamine and of methacholine causing a $20 \%$ fall in $F E V$,$) . The solid line is the line of identity and the broken$ lines indicate one doubling dose from the line of identity.

* Multiple data points superimposed.

for smokers, $0.78(0 \cdot 18)$ for atopic subjects). The mean within subject difference between $\mathrm{PD}_{20} \mathrm{H}$ and $\mathrm{PD}_{20} \mathrm{M}$ values was $0.034 \log _{10} \mu \mathrm{mol}$ and the standard deviation of the difference was $0.472 \log _{10} \mu \mathrm{mol}$. When the 48 subjects who had a measurable $\mathrm{PD}_{20}$ with both agents were considered separately the regression coefficient (SE) was 0.56 (0.14) (p < 0.001).

\section{REPEATABILITY OF HISTAMINE AND}

METHACHOLINE PD $_{20}$ VALUES

Of the 96 subjects who attended for repeat tests with the same agent, 52 had a measurable $\mathbf{P D}_{20}$ on at least one occasion ( 25 with histamine and 27 with methacholine - table and figs 3 and 4). The standard deviation for the difference between repeat $P_{20}$ measurements was $0.55 \log _{10} \mu \mathrm{mol}$ for histamine and

Number of $P D_{20}$ estimates obtained in group $A$ ( random sample) and group B (subjects with wheeze in last year)

\begin{tabular}{lllll}
\hline Test & Group & $\begin{array}{c}P D_{20} \mathrm{H} \\
<8 \mu \mathrm{mol}\end{array}$ & \multicolumn{2}{l}{$P D_{20} M$} \\
\cline { 5 - 6 } & $<12 \mu \mathrm{mol}$ & $<24 \mu \mathrm{mol}$ \\
\hline $\begin{array}{c}\text { Histamine/ } \\
\text { methacholine }\end{array}$ & $\mathrm{A}(\mathrm{n}=108)$ & 11 & 16 & 25 \\
$\begin{array}{c}\text { Histamine/ } \\
\text { histamine }\end{array}$ & $\mathrm{B}(\mathrm{n}=95)$ & 48 & 51 & 67 \\
$\begin{array}{c}\text { Methacholine/ } \\
\text { methacholine }\end{array}$ & $\mathrm{B}(\mathrm{n}=46)$ & $25^{*}(15)$ & - & - \\
\hline
\end{tabular}

*Uncensored $\mathrm{PD}_{20}$ on at least one occasion; ( ) indicates uncensored $\mathrm{PD}_{20}$ on both occasions.

$\mathrm{PD}_{20} \mathrm{H}\left(\mathrm{PD}_{20} \mathrm{M}\right.$ ) - provocative dose of histamine (methacholine) causing a $20 \%$ fall in $\mathrm{FEV}_{1}$.
$0.45 \log _{10} \mu \mathrm{mol}$ for methacholine, from which the $95 \%$ range for a single estimation of $\mathrm{PD}_{20}$ was \pm 2.5 doubling doses in the 25 subjects receiving histamine and $\pm 2 \cdot 1$ doubling doses in the 27 subjects receiving

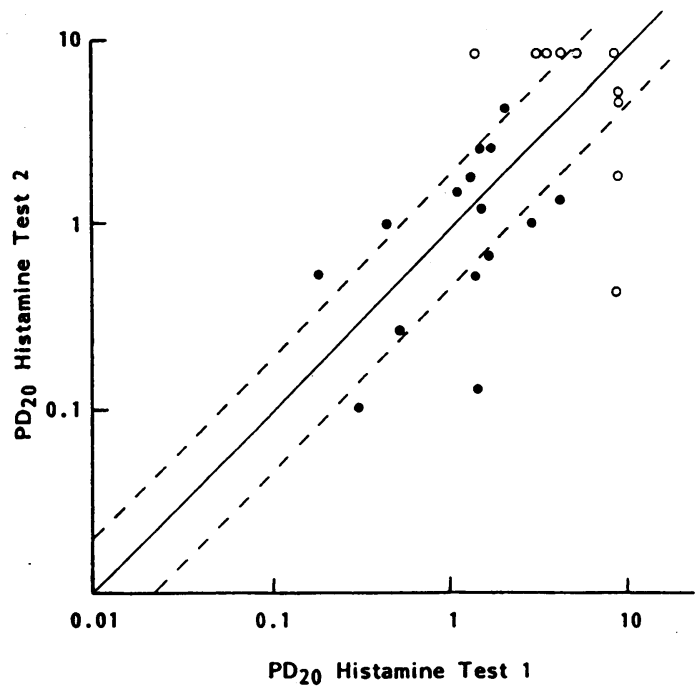

Fig 3 Relation between $P D_{20}$ values from repeat histamine tests. Closed circles represent subjects having a measurable $P D_{20}$ on two occasions and open circles subjects with one measurable and one censored $P D_{20}$; the solid line is the line of identity and the broken line indicates one doubling dose from the line of identity.

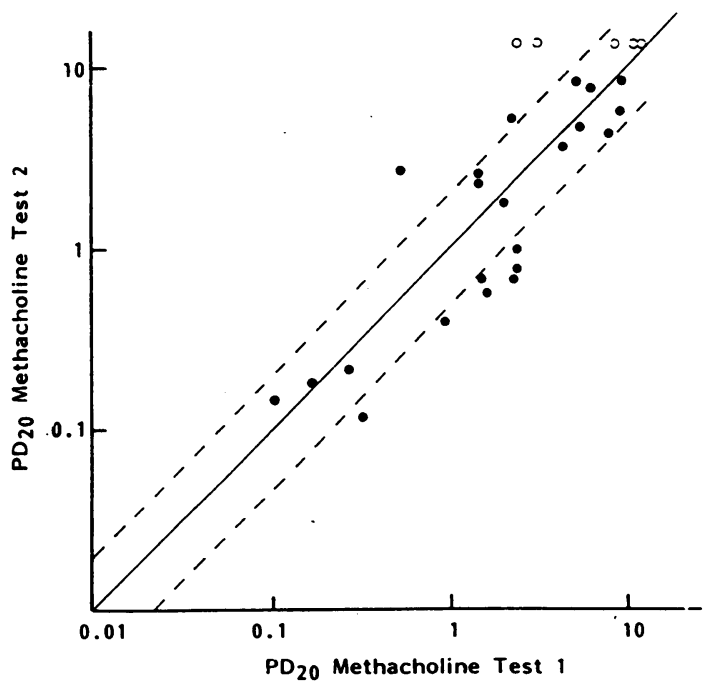

Fig 4 Relation between $P D_{20}$ values from repeat methacholine tests. Closed circles represent subjects having a measurable $P D_{20}$ on two occasions and open circles subjects with one measurable and one censored $P D_{20}$; the solid line is the line of identity and the broken lines indicate one doubling dose from the line of identity. 
methacholine. An uncensored $\mathrm{PD}_{20}$ value was obtained on both occasions in 15 subjects with histamine and 22 subjects with methacholine, and in these subjects the $95 \%$ range for a single estimation was $\pm 2 \cdot 4$ doubling doses for histamine and \pm 1.9 doubling doses for methacholine. Repeatability with methacholine did not differ significantly from that with histamine, whether censored values were included (variance ratio $=1 \cdot 49, \mathrm{p}>0 \cdot 1)$ or excluded (variance ratio $=1 \cdot 46, \mathrm{p}>0 \cdot 1)$.

From the standard deviations of the differences between repeat $\mathrm{PD}_{20}$ measurements the expected within subject standard deviation of the difference between $\mathrm{PD}_{20} \mathrm{H}$ and $\mathrm{PD}_{20} \mathrm{M}$ results was calculated as $0.50 \log _{10} \mu \mathrm{mol}$.

Eleven subjects undergoing repeat histamine tests and 10 undergoing repeat methacholine tests developed symptoms of a cold or a change in the frequency of wheeze, or both, between tests. Excluding values from these subjects did not alter the repeatability figures for either agent significantly. The interval between tests was similar for the two agents (median 7 (range 1-23) days for histamine and 6(1-32) days for methacholine).

\section{ADVERSE EFFECTS}

Side effects were mild with both agents. Histamine caused more voice change than methacholine, both in the first test of all subjects $(21 \% v 11 \% ; \mathrm{p}<0.05)$ and in the subjects who had both agents $(18 \% v 10 \%$; $\mathrm{p}<$ 0.05 ). Of the other adverse effects, only cough occurred with any frequency, and this was similar with histamine and methacholine ( $30 \% v 34 \%$, NS), as was the incidence of any other side effect (17\% v16\%, NS).

\section{Discussion}

The aim of this study was to determine whether histamine or methacholine is the better agent for use in epidemiological surveys of bronchial reactivity. The assessment was made by comparing the number of $\mathrm{PD}_{20}$ estimates, the incidence of side effects, and the repeatability of $P D_{20}$ values with the two agents. The number of $\mathrm{PD}_{20}$ estimates and the incidence of side effects are both dose dependent and therefore need to be considered together.

With any test designed for field studies it is important that side effects are kept to a minimum. We chose $4 \mu \mathrm{mol}$ histamine and $12 \mu \mathrm{mol}$ methacholine as maximum doses because they produced a similar number of mild side effects in a pilot study. In the community study methacholine produced a significantly greater number of $\mathrm{PD}_{20}$ estimates but a lower incidence of adverse effects than histamine in the subjects who completed tests with both agents. As some subjects may have failed to keep their second appointment because of side effects experienced at the first visit we also compared symptoms reported in the first test by all subjects who attended at least once, and methacholine was again the more acceptable agent. A similar conclusion was reached in one previous laboratory study, ${ }^{9}$ in which most of the subjects were asthmatic. We have been able to show in a larger field study that this permits a significantly greater number of $\mathrm{PD}_{20}$ measurements to be made with methacholine, a major advantage in community studies.

We had predicted that $24 \mu \mathrm{mol}$ of methacholine would produce more $\mathrm{PD}_{20}$ estimates than $8 \mu \mathrm{mol}$ of histamine as the two agents have previously been shown to cause a similar degree of bronchoconstriction for a given concentration in $\mathrm{mg} / \mathrm{ml} .^{9}$ Thus, after correction for molecular weight, $8 \mu \mathrm{mol}$ histamine was expected to produce the same effect as $12 \mu \mathrm{mol}$ methacholine. In our study, however, the potency of methacholine is very close to that of histamine (fig 2) with a mean difference between $\mathrm{PD}_{20} \mathrm{H}$ and $\mathrm{PD}_{20} \mathrm{M}$ values of only $0.034 \log _{10} \mu \mathrm{mol}$; the $95 \%$ confidence interval for this difference suggests that the $P_{20} \mathrm{M}$ is likely to be from 0.85 to 1.38 times the $P_{20} \mathrm{H}$.

As only $10-20 \%$ of a random population are likely to have a $20 \%$ fall in $\mathrm{FEV}_{1}$ with acceptable doses of bronchoconstrictor agonist, ${ }^{18}$ we recruited an additional group of subjects who had recently experienced an episode of wheezing and who were therefore more likely to have a measurable $\mathrm{PD}_{20}$, so that enough $P_{20}$ estimates were obtained to enable us to assess repeatability. Whether analysis of repeatability should include subjects who have one censored $\mathrm{PD}_{20}$ or be confined to those with two measurable $\mathrm{PD}_{20}$ values is debatable. "We have analysed both and found methacholine to have slightly better repeatability in both cases, although the difference is not significant. In most laboratory comparisons the repeatability of histamine and methacholine has been similar, ${ }^{912}$ although one author has reported better repeatability with methacholine in subjects recovering from an exacerbation of asthma. ${ }^{13}$ The two agents have not been compared in a community based population before, and there are no published measures of repeatability with either agent in a randomly selected community population. The $95 \%$ ranges for a single estimation are inevitably less good than those seen in the laboratory in selected subjects familiar with the measurement techniques. ${ }^{9121415}$ It may be possible to reduce measurement error in epidemiological studies by altering the challenge test technique, but any modification would have to be assessed in a similar randomly selected population. In the mean time the designs of studies in the community need to take account of the repeatability of the method used.

Histamine challenge tests might be expected a priori 
to be less repeatable than methacholine challenge tests because, in addition to a direct action on bronchial smooth muscle, histamine appears to be more likely than methacholine to cause mucosal oedema, activate irritant receptors, and increase vagally mediated bronchoconstriction. ${ }^{16}$ Despite these possible differences histamine and methacholine challenges are often described interchangeably as tests of non-specific bronchial reactivity, with the implication that they are measuring the same underlying pathophysiological process. If this assumption is true the agreement between $P D_{20} \mathrm{H}$ and $P D_{20} \mathrm{M}$ values should be as close as the agreement between repeat measurements with the same agent. When account is taken of the repeatability of each method the predicted standard deviation for the difference between $P_{20} \mathrm{H}$ and $\mathrm{PD}_{20} \mathrm{M}$ values in the same subject is $0.50 \log _{10} \mu \mathrm{mol}$. This is almost identical to the observed standard deviation of the difference between the two measurements $\left(0.47 \log _{10} \mu \mathrm{mol}\right)$ in the subjects undergoing both tests (the findings are similar if censored values are excluded, the predicted value being 0.44 $\log _{10} \mu \mathrm{mol}$ and the observed value $0.50 \log _{10} \mu \mathrm{mol}$ ). Thus the methods agree as closely as would be expected from a knowledge of the repeatability of each agent. Furthermore, if histamine and methacholine are not measuring the same underlying abnormality the relationship between $\mathrm{PD}_{20} \mathrm{H}$ and $\mathrm{PD}_{20} \mathrm{M}$ might be expected to differ between atopic and non-atopic subjects and between smokers and non-smokers, as increased reactivity in these groups may be produced by different mechanisms. ${ }^{17}{ }^{18}$ In fact, the regression of $\mathrm{PD}_{20} \mathrm{M}$ on $\mathrm{PD}_{20} \mathrm{H}$ values was virtually identical in smokers, non-smokers, and atopic and non-atopic subjects. Thus our findings do not provide support for the idea that histamine and methacholine are measuring different phenomena.

We have shown that when used in an epidemiological study methacholine produces more measurements of non-specific bronchial reactivity than histamine, with less unwanted effects. Methacholine results were also slightly more repeatable. We believe that methacholine is the preferred agent for community studies of bronchial reactivity.

We would like to thank Mrs Susan Cooper, Ms Ros Hill, and Mr Philip Kemp for help with the field work; Dr D Jenkinson and his partners in the Keyworth general practice for their help and cooperation; and the British Lung Foundation for financial support.

\section{References}

1 Burney PGJ, Britton JR, Chinn S, et al. Descriptive epidemiology of bronchial reactivity in an adult population: results from a community study. Thorax
1987;42:38-44.

2 Cockcroft DW, Murdock KY, Berscheid BA. Relationship between atopy and bronchial responsiveness to $\overline{\mathrm{C}}$ histamine in a random population. Ann Allergy $\underset{\Phi}{\overparen{จ}}$ 1984;53:26-9.

3 Cockcroft DW, Berscheid BA, Murdock KY. Unimodal distribution of bronchial responsiveness in a random $\overrightarrow{-}$ human population, Chest 1983;83:751-4.

4 Lee DA, Winslow NR, Speight ANP, Hey EN. $\vec{\omega}$ Prevalence and spectrum of asthma in childhood. Br Med J 1983;286:1256-8.

5 Sears MR, Jones DT, Holdaway MD, et al. Prevalence of $f^{\times}$ bronchial reactivity to inhaled methacholine in Newc Zealand children. Thorax 1986;41:283-9.

6 Townley RG, Bewtra A, Wilson AF et al Segregation analysis of bronchial response to methacholine ${ }^{\mathrm{r}}$ inhalation challenge in families with and without asthma. J Allergy Clin Immunol 1986;77:101-7.

7 Weiss ST, Tager IB, Weiss JW, Munoz A, Speizer FE, Ingram RH. Airway responsiveness in a population $\bar{\varrho}$ sample of adults and children Am Rev Respir Dis 1984;129:898-902.

8 Woolcock AJ, Peat JK, Salome CM, et al. Prevalence of $\vec{\oplus}$ bronchial responsiveness and asthma in a rural adult ${ }^{\circ}$ population. Thorax 1987;42:361-8.

9 Juniper EF, Frith PA, Dunnet C, Cockroft DW, Hargreave FE. Reproducibility and comparison of $\bar{\partial}$ responses to inhaled histamine and methacholine. پِ Thorax 1978;33:705-10.

10 Yan K, Salome C, Woolcock AJ. Rapid method for measurement of bronchial responsiveness. Thoraxo음 1983;38:760-5.

11 Chinn S, Britton JR, Burney PGJ, Tattersfield AE, Papacosta AO. Estimation and repeatability of the? response to inhaled histamine in a community survey. Thorax 1987;42:45-52.

12 Eiser NM, MacRae KD, Guz A. Evaluation and expres- श्र sion of bronchial provocation tests. Bull Euro Physiopathol Respir 1981;17:427-40.

13 Spector SL, Farr RS. A comparison of methacholine and histamine inhalations in asthmatics. $J$ Allergy Clin 3 Immunol 1975;56:308-16.

14 Dehaut P, Rachiell A, Martin RR, Malo JL. Histamine dose-response curves in asthma: reproducibility and sensitivity of different indices to assess response. Thorax 1983;38:516-22.

15 Madsen F, Rathlou NHH, Frolund L, Gerner SvendsonU, Weeke B. Short and long term reproducibility of 0 responsiveness to inhaled histamine: Rt compared to FEV1 as measurement of response to challenge. Eur Jర Respir Dis 1985;67:193-203.

16 Holtzman MJ, Sheller JR, Dimeo M, Nadel JA, Bousheyc HA. Effect of ganglionic blockade on bronchiales reactivity in atopic subjects. Am Rev Respir Dis 1980;122:17-25.

17 Ramsdale EH, Roberts RS, Morris MM, Hargreave FE. Differences in responsiveness to hyperventilation ando methacholine in asthma and chronic bronchitis. Thorax 1985;40:422-6.

18 Du Toit JI, Woolcock AJ, Salome CM, Sundrum R, Black JL. Characteristics of bronchial hyperresponsive-尺 ness in smokers with chronic air-flow limitation. Ans Rev Respir Dis 1986;134:498-501. 